\title{
Divorcio incausado: una urgente actualización normativa
}

\section{Uncaused Divorce: An Urgent Normative Update}

Sergio Núñez Dávila *

Recibido / Received: 09/05/2021

Aceptado / Accepted: 24/10/2021

DOI: $10.18272 /$ ulr.v8i2.2280

Citación:

Núñez Dávila, S. «Divorcio incausado: una urgente actualización normativa». USFQ Law Review, Vol 8, no 2, octubre de 2021, pp. 157-181, doi: 10.18272/ulr.v8i2.2280. 


\section{RESUMEN}

Desde sus orígenes en el Ecuador, la figura civil del divorcio se rige por un sistema causalista. Para que el juez pueda declarar la disolución del vínculo matrimonial, es preciso que se verifiquen -y se prueben- una serie de elementos fácticos prescritos en la ley. Como es lógico, estos requisitos legales dificultan la libre terminación del vínculo y reducen el problema a uno de carácter probatorio. Sin embargo, este sistema fue introducido en el Ecuador hace ya más de cien años. Actualmente, el divorcio por causales resulta incompatible con un Estado en el que prima la libertad y la autonomía de la voluntad de sus ciudadanos. La libertad para decidir quién ser. El presente trabajo propone la mejor vía de escape para este anticuado régimen: un divorcio incausado y unilateral. No se requiere más que la voluntad de uno de los cónyuges, independientemente de las razones personales que lo motivaron a tomar esa decisión. Nada tendrá que ser probado ni justificado, pues el Estado no es acreedor de explicaciones tan íntimas. Su rol no consiste en decidir sobre la vida privada de las personas. Por el contrario, el Estado debe protegerlas para que por sí mismas tengan la libertad para decidir qué es lo que mejor les conviene. El divorcio incausado, por lo tanto, es respetuoso con el derecho al libre desarrollo de la personalidad, a la intimidad y protección familiar, además de valorar -por sobre todo- la autonomía de las personas. Es necesario introducirlo en el ordenamiento jurídico ecuatoriano para, por fin, dotar del elemento libertad a su régimen matrimonial.

\section{Palabras clave}

Divorcio; divorcio incausado; libre desarrollo de la personalidad; autonomía de la voluntad; derecho a la privacidad familiar; derecho a la protección familiar; proteccionismo; paternalismo; perfeccionismo

\section{Abstract}

Since its origins in Ecuador, the civil figure of divorce has followed a causal system. In order for the judge to dissolve a marriage, some factual evidence required by the law has to be verified and proven. Unsurprisingly, these legal requirements restrict the dissolution and reduce the problem to a probatory issue. Nevertheless, this system was introduced in Ecuador more than a hundred years ago. Nowadays, the causal system is incompatible with a State that enhances freedom and individual autonomy as one of its core legal values. The freedom to decide who to be. To assess this issue, the present study pretends to propose an alternative yet optimum solution: an uncaused and unilateral divorce. Nothing should be proven or justified, since the State is no creditor of such intimate explanations. Its role does not consist in taking personal decisions for its citizens. Instead, it must protect individuals so they can freely make their own choices about their personal life. Therefore, an uncaused and unilateral divorce is congruent and respectful with fundamental cons- 
titutional rights such as the right to the unhindered development of the personality, the right of the individuals to the protection of the family and of its privacy, besides enhancing, above all, the autonomy of the will. It is required to be introduced in the Ecuadorian legal system to reconcile the institution of marriage with the deeply desired freedom.

\section{KEYWORDS}

Divorce; uncaused divorce; right to the unhindered development of the personality; autonomy of the will; right to familiar privacy; right to the protection of the family; protectionism; paternalism; perfectionism

\section{INTRODUCCIÓN}

"I set out on this ground, which I suppose to be self-evident, that the earth belongs in usufruct to the living: that the dead have neither powers nor rights over it."

Thomas Jefferson a James Madison, $1789^{1}$

Hasta finales del siglo XX, Chile no legalizaba el divorcio. Pero las personas sí querían divorciarse. Querían separarse y romper el vínculo a como fuera posible. ¿Cómo hacerlo en un sistema que no contempla esta figura?

Como es bien conocido, la nulidad de un acto jurídico es la sanción que la ley prescribe para aquellos casos en los que no se cumple con todos los requisitos legales que el acto en cuestión demanda. Si, por ejemplo, se celebra un contrato de compraventa de un bien inmueble mediante escritura privada, ese contrato no podrá surtir los efectos propuestos. Si se realiza una donación a la fuerza, bajo amenazas graves e intimidatorias, ese contrato tendrá un vicio del consentimiento. Cuando el juez declare la nulidad de estos contratos defectuosos, esta opera retroactivamente. No se disuelve un vínculo que nació y tuvo vida jurídica. Por el contrario, se presume que nunca existió.

A diferencia del divorcio, la nulidad no es invento nuevo. Esta ya existía mucho tiempo atrás. Por lo tanto, las personas en Chile no pretendían romper el vínculo matrimonial (pues era irrompible); lo que intentaban $-y$ vaya que lo lograban- era anularlo. ${ }^{2}$

Así, durante muchos años se simularon juicios en los que se demandaba la

1 Madison, James. The Papers of James Madison, vol. 12, 2 March 1789-20 January 1790 and supplement 24 October 1775 24 January 1789, ed. Charles F. Hobson and Robert A. Rutland. (Charlottesville: University Press of Virginia, 1979), 382-388. Citado en Jefferson, Thomas. To James Madison from Thomas Jefferson, 6 September 1879. Paris: Founders Online, National Archives, 1879. https://bit.ly/2R7N3c7.

2 Hernán F. Corral Talciani, "Indisolubilidad Matrimonial y Divorcio ante el Derecho Civil", Revista Chilena de Derecho 19 , no. 1 (Abril 1992): pág. 36, https://bit.ly/2RE2BEi. 
nulidad del matrimonio. Ambos cónyuges, astutamente, simulaban un proceso en el que alegaban -uno como actor y otro como demandado- que el matrimonio se había celebrado ante autoridad incompetente. Para tal efecto, conseguían dos testigos que certificaran fraudulentamente que aquel no era el lugar de residencia de ninguno de los dos al momento de la celebración del matrimonio. ${ }^{3}$ El vínculo matrimonial no se disolvía, pues la disolución presupone su preexistencia. Lo que ocurría, entonces, es que después de la declaración judicial de nulidad, ese matrimonio se reputaba como no haber existido jamás. ${ }^{4}$

¿Cuál es la solución ante un caso como este? Habrá quien piense que lo adecuado es dificultar la simulación. Así las personas no se saldrán con la suya burlando al sistema. Para tal efecto, se podría poner un plazo de prescripción de la acción de nulidad. Otra posibilidad sería dotar de competencia a todas las autoridades, indiferentemente de la residencia de los contrayentes. Pero no. La ley no puede ser ciega ante las demandas sociales. ${ }^{5} \mathrm{Y}$ así fue como se legalizó el divorcio en Chile.

Análogamente, el divorcio por causales no es un reflejo de la conducta e idiosincrasia de los ecuatorianos. En primer lugar, porque la Iglesia Católica ya no tiene el mismo poder de influencia que tenía hace cien años. El tinte religioso en el entendimiento del divorcio cada vez es menor. En segundo lugar -y más importante aún- es que sucede lo mismo que en Chile: las personas se divorcian de todas maneras. Y si no hay una causal que invocar, la crearán artificialmente.

Nuevamente, el Estado ecuatoriano se encuentra ante una similar disyuntiva. Podría, por un lado, desconocer la realidad. ¿Cómo hacerlo? Fortaleciendo las causales. Podría vigorizar la exigencia probatoria de las mismas o asegurarse, a capa y espada, de que las causales no sean fabricadas por los abogados. Pero por el otro lado, y con mayor sensatez, podría reajustar el sistema para que responda a la realidad y respete derechos fundamentales constitucionalmente reconocidos.

El presente trabajo es una propuesta de reajuste. El divorcio por causales, antes que nada, vulnera varios derechos fundamentales consagrados constitucionalmente. Violenta el derecho al libre desarrollo de la personalidad toda vez que las personas se encuentran constreñidas a permanecer en una relación -la más estrecha de todas- en la que ya no quieren estar. Vulnera, también, el derecho a la privacidad familiar, pues el Estado se excede en sus atribuciones al exigir

3 Curioso es el emblemático caso en el que el cónyuge pidió la nulidad del matrimonio alegando que tal no era su lugar de residencia al momento del matrimonio. Ese mismo era el domicilio que figuraba en los datos del actor en la demanda. Ibid., 36.

4 Ibid., 36-38.

5 Ibid. 
de sus ciudadanos explicaciones íntimas y familiares. Además, quebranta el derecho a la protección familiar al perpetuar artificialmente un ambiente doméstico hostil.

Para tal efecto, la mejor propuesta posible es la introducción de un divorcio incausado y unilateral. Al no exigir causal ni explicación alguna, faculta a las personas a desarrollar su autonomía e independencia de la mejor manera. Se propondrá en el ordenamiento ecuatoriano la instauración de una figura que, ante todo, introduzca un elemento tan deseado en materia matrimonial: la libertad.

\section{Historia del MATrimonio en el ECUAdor}

Desde su primera Constitución en el año 1830, el Ecuador era un Estado abiertamente confesional. "En el nombre de Dios, autor y legislador de la sociedad", ${ }^{6}$ rezaba su preámbulo. El rol que la Iglesia cumplía dentro de las labores burocráticas del Estado era absolutamente protagonista. En ese entonces, la Iglesia Católica estaba a cargo de dirigir varias instituciones educativas y culturales del país, además de ser el exclusivo ente regulador del matrimonio, su celebración y sus consecuencias patrimoniales. ${ }^{7}$ En el mismo sentido, el artículo 99 del Código Civil del año 1860 prescribía: "Toca a la autoridad eclesiástica decidir sobre la validez del matrimonio que se trata de contraer o se ha contraído". ${ }^{8}$ Naturalmente, en un sistema matrimonial regulado monopólicamente por el derecho canónico, el divorcio estaba categóricamente proscrito, pues la piedra angular del matrimonio eclesiástico, de esta figura divina, era precisamente la indisolubilidad de su vínculo.

Sin embargo, con Eloy Alfaro y la Revolución Liberal llegó el laicismo al Ecuador. Se introdujo la Ley de Matrimonio Civil que entró en vigencia en el año 1903. Trajo consigo fundamentalmente dos novedades. Primero, le arrebató a la Iglesia la facultad exclusiva de regular el matrimonio. Segundo, instauró la figura del divorcio vincular. ${ }^{9}$ Esta, en realidad, era su razón de fondo. Si la Ley no creaba su propio matrimonio, no hubiera podido crear su propio divorcio.

Previsiblemente, la Ley de Matrimonio Civil no estuvo exenta de fuertes críticas. Los sectores conservadores y religiosos de la sociedad no demoraron en manifestar su descontento. Al respecto, el reconocido jurista y arzobispo de Guayaquil, Juan Larrea Holguín, afirmaba que el matrimonio civil regula temas que le son naturalmente ajenos:

6 Constitución Política del Ecuador, 23 de septiembre de 1830

7 Enrique Ayala Mora, "El laicismo en la historia del Ecuador", Procesos: Revista Ecuatoriana de Historia 8, (1996): 5, http:// hdl.handle.net/10644/1257.

8 Art. 99, Código Civil [CC 1860], Registro Auténtico de 3 de diciembre 1860.

9 Divorcio vincular o perfecto es aquel que disuelve el vínculo matrimonial, mientras que el divorcio relativo, imperfecto o la separación de cuerpos, es aquel que exime a los cónyuges de algunas de las obligaciones conyugales, pero no los desvincula jurídicamente. Este segundo sí era aceptado, a regañadientes, por la Iglesia Católica. 
Se sustituye la institución natural y divina por una arbitraria convención de hombres; se cambian los sólidos cimientos por bases de arena. ¿¿Nos podremos quejar después de la ruina y destrucción de la sociedad? Si es difícil obedecer a Dios, más difícil es obedecer a los hombres, y con mayor razón si son ignorantes y se dejan llevar de las pasiones. ${ }^{10}$

Así, a regańadientes y en contra de la voluntad de muchos, fue como se introdujo el matrimonio civil en el ordenamiento jurídico ecuatoriano. Perdura hasta el día de hoy.

\section{Sistema Causalista}

Con la entrada en vigencia de esta Ley, el sistema era causalista. El juez puede disolver el vínculo matrimonial únicamente cuando se configure alguna de las causales prescritas en la ley. En el año 1903, la única causal existente era el adulterio de la mujer (y no del hombre). Varias reformas surgieron posteriormente con relación a las causales. En el año 1904 se añadieron otras dos: el concubinato público y escandaloso del marido, y la sentencia judicial que determina que uno de los cónyuges fue autor o cómplice de un crimen contra la vida del otro. ${ }^{11}$

En el año 1910 se introdujo el divorcio por mutuo consentimiento. ${ }^{12}$ Para el año 1960, el cuerpo normativo que regulaba las causales de divorcio era el Código Civil. Este contemplaba trece causales, incluyendo entre ellas a la sevicia, las injurias graves y la actitud hostil en la relación, las amenazas graves y frecuentes de un cónyuge contra la vida del otro, la enfermedad incurable y contagiosa de uno de los cónyuges, y la impotencia sexual. ${ }^{13}$ Las reformas y derogatorias esporádicas no cesaron desde entonces y, actualmente, el artículo 110 del Código Civil contiene nueve causales de divorcio. Paralelamente, el divorcio por mutuo consentimiento encuentra cabida en el artículo 107 del mismo cuerpo normativo. ${ }^{14}$

\section{Divorcio SANCIÓN Y DIVORCIO REMEDIO}

Es fundamental para el estudio en cuestión entender cuál es el origen y las consecuencias de un sistema causalista. Al ser producto de una lucha entre la Iglesia y la Revolución Liberal, la figura del divorcio tenía necesariamente que ser de aplicación harto inflexible.

10 Juan Larrea Holguín, Derecho Civil del Ecuador: Derecho Matrimonial, Tomo II. (Quito: Corporación de Estudios y Publicaciones, 1985), 28

11 Artículo 22, Ley de Matrimonio Civil de 3 de octubre de 1902, reformado en 1904.

12 Id., reforma de 1910.

13 Art. 132, Código Civil, [CC 1960], Registro Oficial Suplemento 1202 de 20 de agosto de 1960.

14 Código Civil, [CC], Registro Oficial Suplementario 46 de 24 de junio de 2005. 
El sistema causalista lo logra: permite el divorcio, pero con excesiva renuencia. Con la mayoría de las causales, ${ }^{15}$ el divorcio es una sanción para el cónyuge culpable de desencadenar la ruptura. ${ }^{16}$ Esta sanción se fundamenta en el incumplimiento contractual del matrimonio y pone a los ex cónyuges en una relación fundada en la culpabilidad y en la inocencia. ${ }^{17}$ En este sentido, la Corte Nacional de Justicia ha ilustrado el concepto de divorcio sanción, tal como se lo entendía en el ordenamiento ecuatoriano, con claridad:

Se precisa que, las causales de divorcio, en nuestra legislación, tienen relación directa con el incumplimiento de los deberes conyugales, por ejemplo, con el fin de obtener el divorcio, solo deben ser invocadas por el o la cónyuge que se creyere agraviada/o. La doctrina refiere este tipo de separaciones como divorcio sanción, puesto que el legislador ha establecido sanciones para el cónyuge que hubiere incurrido en una de las causales ${ }^{18}[\ldots] .{ }^{19}$

Sin embargo, la misma sentencia de la Corte Nacional de Justicia aborda el concepto desde una perspectiva un tanto distinta. Explica que el derecho "no puede obligar a dos personas a vivir juntas", pues hacerlo sería vulnerar varios derechos constitucionales como "el derecho al libre desarrollo de la personalidad, a la intimidad, a la dignidad en su faceta de autodeterminación y toma de decisiones libres sobre asuntos personales sin injerencias indebidas del Estado". ${ }^{20}$ Además de que el divorcio es considerado por la legislación ecuatoriana como una sanción o castigo, la Corte consideró la posibilidad de que sea también visto como una salida a una situación tormentosa y conflictiva. Fue un buen primer inicio.

En ese sentido, el entendimiento del divorcio ha experimentado un punto de inflexión. Ya no se lo concibe como un castigo que debe sufrir el cónyuge culpable de la disolución conyugal. Empieza a ser percibido como un remedio para una relación que se sostiene en la vida jurídica pero no en la realidad. ${ }^{21}$ El divorcio remedio abandona la idea de que uno de los cónyuges es culpable y merecedor de una sanción. Lo que prima es la voluntad

15 Por ejemplo, la causal tercera del artículo 110 del Código Civil prescribe que será causal de divorcio "el estado habitual de falta de armonía de las dos voluntades en la vida matrimonial". Evidentemente, esta causal no contempla la relación culpable-inocente. Sin embargo, el resto de causales sí que lo hacen: el adulterio de uno de los cónyuges, los tratos crueles, las amenazas graves de un cónyuge contra la vida del otro, la tentativa de uno de los cónyuges contra la vida del otro, etcétera.

16 Corral, "Indisolubilidad matrimonial y divorcio", 41.

17 Ana Albarracín Cogollo, "La reparación de los perjuicios ocasionados por el divorcio en la legislación colombiana", Temas Socio-Jurídicos 30, no. 62 (Febrero 2013): 196-197. https://bit.ly/2SFyLQn.

18 Esas sanciones, en el año 2014, eran las siguientes: el cónyuge culpable perdía la custodia de los hijos (art. 108, numeral cuarto del CC); no tendrá derecho a recibir la quinta parte de los bienes del cónyuge para su congrua sustentación, con ciertas excepciones (art. 112 del CC); el cónyuge inocente podrá revocar las donaciones realizadas al cónyuge culpable (art. 114 del CC); en caso de que la causal sea la de abandono, para la liquidación de la sociedad conyugal los bienes adquiridos en virtud del trabajo del cónyuge abandonado, en dicho período, no entrarán al haber absoluto de la sociedad (art. 116 del CC)

19 Sentencia No. 0170-2014, Corte Nacional de Justicia, Sala Especializada de la Familia, Nińez y Adolescencia, 19 de agosto de 2014, 5.3.2.

20 Id.

21 Mabel Rivero de Arhancet, Beatriz Ramos Cabanellas, "El divorcio en el derecho uruguayo", en El divorcio en el derecho iberoamericano, ed. Ángel Acedo, Leonardo B. Pérez Gallardo (México, Ubijus, 2009), 616. 
de disolver un vínculo jurídico que por alguna razón — que al Estado no le corresponde conocer- se volvió incompatible con el vínculo fundacional del matrimonio: el afectivo.

La jurisprudencia ecuatoriana ya ha reconocido explícitamente al divorcio como un remedio. La Corte Nacional de Justicia, en el año 2018, lo entendió de esa manera al manifestar que la disolución matrimonial "se da como un remedio para las situaciones vividas en protección de la esfera emocional y física de los cónyuges". ${ }^{22}$ Además, añadió que mantener en la vida jurídica, en contra de la voluntad de los cónyuges, una relación matrimonial de naturaleza duelista y conflictiva atenta contra su derecho a la protección familiar y al libre desarrollo de la personalidad, ambos consagrados en los artículos 66 numeral 5 y 67 de la Constitución de la República del Ecuador. ${ }^{23}$

¿Qué papel juega un sistema causalista en un Estado cuyos jueces reconocen expresamente al divorcio como un remedio? Ninguno. Ante esta insalvable irreconciliabilidad, el sistema causalista debe ser desechado del ordenamiento jurídico ecuatoriano.

\section{DiVORCIO POR CAUSALES VS. DIVORCIO REMEDIO}

El anacrónico sistema causalista es incompatible con esta nueva percepción del divorcio. Si el divorcio vincular ya no es entendido como una sanción para el cónyuge infractor, sino que es percibido como una solución para una ruptura sentimental irremediable, entonces el sistema causalista ya no tiene cabida en el ordenamiento jurídico ecuatoriano. Un sistema causalista perenniza el carácter supuestamente sancionatorio del divorcio. Es el medio adecuado para que el juez sancione con el divorcio al cónyuge infractor. Para tal efecto, el Código Civil contempla sanciones civiles para el cónyuge culpable, tales como quitarle el derecho a percibir la quinta parte de los bienes del otro cuando se encuentre en situación de pobreza ${ }^{24} \mathrm{o}$ facultar al inocente para que revoque las donaciones que al culpable otorgó. ${ }^{25}$

Ante esta manifiesta desavenencia entre el divorcio remedio y el sistema causalista, es preciso una nueva figura: el divorcio incausado. Esta coexiste pacíficamente con el divorcio remedio, pues no pretende buscar culpables que sean merecedores de sanción. Ergo, el divorcio incausado es mejor bienvenido dentro del ordenamiento jurídico ecuatoriano.

22 Causa No. 09334-2017-00528, Corte Nacional de Justicia, Sala Especializada de la Familia, Niñez, Adolescencia y Adolescentes Infractores, 25 de junio de 2018.

23 Constitución de la República del Ecuador, Registro Oficial 449, 20 de octubre de 2008, reformada por última vez R.O. Suplemento 181 de 15 de febrero de 2018.

24 Artículo 112, CC

25 Artículo 114, CC. 
Es así como el divorcio incausado reajusta el sistema jurídico. El divorcio remedio significó un progreso de derechos, pero el divorcio por causales lo estanca. El divorcio incausado, entonces, devuelve la armonía al ordenamiento jurídico ecuatoriano al compatibilizar el procedimiento del divorcio (sin causales) con el entendimiento que de él se tiene. Si el divorcio es un remedio, entonces debe necesariamente ser incausado.

\section{Problemas del divorcio con causales}

Esta rotunda irreconciliabilidad es solo el inicio del problema. También las causales han caído en desuso. De los censos realizados por el Instituto Nacional de Estadística y Censos del Ecuador (INEC), se concluye que durante los años $2019^{26}$ y $2020,{ }^{27}$ solo una de las causales (de las nueve que hay) tiene una recurrencia levemente significativa: el abandono injustificado de uno de los cónyuges. En el ańo 2019, el 66.4\% de los divorcios fueron por mutuo consentimiento (ya sea por vía judicial o notarial), mientras que la causal de abandono fue el fundamento del $28.6 \%$ de divorcios. Ninguna otra causal superó el 2.5\% ${ }^{28}$ En el 2020, considerando que en el mes de abril no hubo ni un solo divorcio (por la pandemia), el divorcio por mutuo consentimiento ascendió al $71.5 \%$ y el divorcio por abandono descendió al $22.5 \%$. Ninguna de las restantes causales representó un porcentaje mayor del $2.4 \%$ de los divorcios en el Ecuador. ${ }^{29}$

No solo que es incompatible con el divorcio remedio y sus causales muy rara vez se invocan. Este sistema es a todas luces violatorio de varios derechos fundamentales consagrados constitucionalmente. Al desconocer la autonomía de la voluntad de las personas, violenta vehementemente el derecho al libre desarrollo de la personalidad, el derecho a la privacidad e intimidad familiar, y el derecho a la protección familiar.

Todas estas vulneraciones, empero, son producto de que el Estado se excede en sus atribuciones. El Estado debe proteger a sus ciudadanos, no decidir por ellos.

\subsection{El rol proteccionista (y no paternalista) Del Estado}

Como es bien conocido, ciertas normas del derecho de familia son de orden público. El Estado tiene particular interés en las relaciones familiares, pues la

26 Instituto Nacional de Estadística y Censos [INEC], Registro Estadística Matrimonios y Divorcios 2019. Quito: Ecuador en Cifras, 2020, 23. https://bit.ly/3evItgL.

27 INEC, Registro Estadística de Matrimonios y Divorcios 2020. Quito: Ecuador en Cifras, 2021, 21. https://www.ecuadorencifras.gob.ec/documentos/web-inec/Poblacion_y_Demografia/Matrimonios_Divorcios/2020/Boletin_tecnico_myd_2020. pdf.

28 INEC, Registro Estadística de Divorcios, 2019

29 INEC, Registro Estadística de Divorcios, 2020. 
familia es el núcleo fundamental de la sociedad. No obstante, por esa misma razón - por la relevancia que tiene la institución familiar en la vida de las personas- el Estado debe tener los límites de su intervención bien trazados.

El Estado ecuatoriano es pluralista. ${ }^{30}$ Reconoce la existencia de una muy considerable diversidad en el seno de su sociedad. Tal es el punto de reconocimiento, que contempla un sistema jurídico distinto al ordinario: la justicia indígena. $\mathrm{Al}$ aceptar que existe más de una cosmovisión y modo de ver la vida, está reconociendo que no hay una sola forma ideal de vivirla. Esa es la razón por la que existe, por ejemplo, el derecho a la igualdad. Si todas las personas fueran absolutamente iguales, no existirían motivos para discriminar. Pero al ser todos tan distintos, existen razones (injustificadas, por supuesto) para discriminar y eso es precisamente lo que el derecho a la igualdad pretende evitar. $^{31}$

Reconociendo y aceptando estas diferencias, el Estado no podría imponer en sus ciudadanos un determinado modo óptimo de vivir. Sería arbitrario hacerlo, pues existen tantos modelos de virtud ética cuantos individuos viven y respiran. Por eso las políticas perfeccionistas no se justifican. El Estado debe limitarse a proteger a las personas para que sean ellas mismas las que tomen las decisiones más importantes de sus vidas.

Con motivos de determinar la constitucionalidad de una norma que obliga a los ciudadanos a utilizar el cinturón de seguridad, la Corte Constitucional colombiana ha trazado la línea divisoria entre una política proteccionista y una perfeccionista o paternalista. ${ }^{32}$ Será proteccionista aquella que proteja a las personas de tal manera en que se les garantice un adecuado desarrollo de la personalidad con base en su autonomía personal, sin imponer un modelo ideal de realización personal. Es decir, una política es justificada cuando no se funda "en la imposición coactiva de un modelo de virtud sino que pretende[n] proteger los propios intereses y convicciones del afectado". ${ }^{33} \mathrm{~A}$ pesar de que es una obligación que desea salvaguardar al individuo, no le está diciendo cómo vivir ni qué tipo de virtud moral adoptar. Le obliga, en cambio, a protegerse a sí mismo para que pueda escoger la ruta moral que mejor le convenga.

Caso distinto es el de una política perfeccionista o paternalista. Estas buscan guiar a las personas por un determinado camino hacia la verdad. Pretenden imponer autoritariamente una forma ética de vivir. Estas medidas son injustificadas porque consisten "en la imposición coactiva a los individuos de modelos de vida y de virtud contrarios a los que ellos profesan, lo cual obviamente

30 Artículos 1 y 3.3, Constitución de la República del Ecuador.

31 Como el lector comprenderá, no se hace referencia a la discriminación positiva o acción afirmativa, que en algunos casos no solo es aceptable, sino también deseable.

32 Sentencia No. 309-97, expediente D-1511, Corte Constitucional de Colombia de 25 de junio de 1997, pág. 1.

33 Id. 
contradice la autonomía, la dignidad y el libre desarrollo de la persona" ${ }^{34}$ Así la Corte justificó la obligatoriedad del uso de cinturón de seguridad. Es prudente admitir, manifestó la Corte, que nadie se realiza personalmente al exponer su vida mientras conduce. ${ }^{35}$ ¿Hubiera podido decir lo mismo sobre el matrimonio y el divorcio, siendo estos tan relevantes para la (in)felicidad de las personas?

Es menester cuestionarse hacia dónde apunta un sistema de divorcio por causales. ¿Pretende este régimen proteger a las personas, como el cinturón de seguridad, para que puedan decidir libremente sobre sus vidas? Como el sistema dificulta el divorcio, en realidad no está protegiendo a los individuos para que puedan escoger con libertad. Está, directamente, escogiendo por ellos. Y lo que escoge no es cualquier cosa: es su estado civil. Obliga a prolongar forzosamente una relación jurídica que perdió su piedra angular: el afecto y el plan conjunto de vida. El Estado, cual padre, considera que la mejor forma de vivir es a través del matrimonio y que, por eso, la necesidad de dificultar su disolución se encuentra justificada. No solo es una política paternalista, sino que es también una lección moral.

Previsiblemente, suele decirse que mediante políticas proteccionistas se debe proteger al matrimonio. Que al ser la familia el núcleo fundamental de la sociedad, el matrimonio merece especial resguardo. Ergo, que un sistema incausado debilitaría los cimientos sobre los cuales se funda la sociedad. Pero este argumento no se sostiene. Es un intento de disfrazar una política paternalista - que intenta imponer el matrimonio como virtud moral_ con una que lo que quiere, en cambio, es protegerlo. Además, pasa por alto dos cuestiones fundamentales. La primera es que el matrimonio forzosamente prolongado rápidamente adquiere un aura conflictiva. La segunda es que un divorcio sanción (por causales), durante todo el iracundo proceso judicial, genera un "alto desgaste físico y emocional" en los cónyuges y en sus familiares. ${ }^{36}$ Que quede claro: dificultar el divorcio no fortalece el matrimonio. Lo que sucede es todo lo contrario: lo desprestigia y le quita valor. Las personas, al ver este tipo de situaciones que "ponen trabas y obstáculos a la libertad, [...] terminan optando por unión libre”. ${ }^{37}$ Sensatamente, preferirán evitar estos penosos escenarios.

\subsection{SOBRE EL DERECHO AL LIBRE DESARROLLO DE LA PERSONALIDAD}

Poder desarrollar la propia personalidad con autonomía es una de las dimensiones más importantes en la vida del ser humano. La facultad de autodeter-

34 Id, 2.

35 Id.

36 Exposición de Motivos, Decreto No. 442 [Por medio del cual se cual modifica el Código Civil del Estado de México y del Código de Procedimientos Civiles del Estado de México]. Gaceta Oficial de Gobierno de 3 de mayo de 2012.

37 Rosario Movilla Suárez, "Divorcio incausado", Revista Derectum 1, no. 2 (Diciembre 2016): 63, https://bit.ly/3o2vUN9. 
minación es un presupuesto básico para la tranquilidad del espíritu. No por casualidad es tan relevante la diferenciación entre una medida proteccionista y una paternalista.

Esta libertad de autodeterminación, al ser tan trascendente en el desarrollo individual, encuentra un amplio reconocimiento jurídico. Se materializa constitucionalmente, dentro de los derechos de libertad, como el derecho al libre desarrollo de la personalidad. ${ }^{38}$ La Corte Constitucional no ha dejado de desarrollar este concepto y ha establecido que "es la facultad que tienen las personas para autodeterminarse, decidir sus propios fines y escoger los medios para alcanzarlo, siempre que se respeten los derechos de las otras personas". 39

La Corte Constitucional ecuatoriana, en la famosa sentencia sobre el matrimonio igualitario, cita a la Corte Constitucional colombiana para desarrollar el derecho al libre desarrollo de la personalidad:

...la posibilidad de adoptar, sin intromisiones ni presiones de ninguna clase, un modelo de vida acorde con sus propios intereses, convicciones, inclinaciones y deseos, siempre, claro está, que se respeten los derechos ajenos y el orden constitucional. [...] Este derecho de opción comporta la libertad e independencia del individuo para gobernar su propia existencia y para diseñar un modelo de personalidad conforme a los dictados de su conciencia, con la única limitante de no causar un perjuicio social. Se configura una vulneración del derecho al libre desarrollo de la personalidad cuando a la persona se le impide, de forma arbitraria, alcanzar o perseguir aspiraciones legítimas de vida o valorar y escoger libremente las circunstancias que dan sentido a su existencia..$^{40}$

El matrimonio y su terminación no es asunto baladí. Debido al inmenso valor social y emocional que tiene para los contrayentes, es un elemento esencial en la vida de las personas. Tan valioso es para el desarrollo individual de una persona, tan arraigado en los sentimientos y valores más profundos en la vida de un individuo, que la decisión no puede quedar en manos del Estado.

Para que una persona pueda desarrollar su personalidad con libertad, poder divorciarse por decisión unilateral e incluso en contra de la voluntad del otro cónyuge, sin necesidad de invocar causal alguna, debe ser el requisito número uno. ¿Con qué justificación puede el Estado obstaculizar tamaña decisión personal? Pocas cosas son más importantes para la felicidad de un individuo que poder escoger con quién pasar el resto de su vida. El divorcio por causales vulnera enérgicamente el derecho al libre desarrollo de la personalidad.

38 Art. 66.5, Constitución de la República del Ecuador.

39 Sentencia No. 11-18-CN/19, Corte Constitucional de Ecuador, 12 de junio de 2019, párr. 167.

40 Sentencia No. C-336-08, expediente D-6947, Corte Constitucional de Colombia, 16 de abril de 2008. 


\subsubsection{DERECHOS DE TERCEROS}

Como ninguno lo es, el derecho al libre desarrollo de la personalidad tampoco es absoluto. La facultad de autodeterminación es admisible únicamente hasta el punto en el que no interfiera con derechos de terceros. Es un condicionamiento evidentemente justificado, pues barbaridades se podrían cometer so pretexto de ser una manifestación del desarrollo de la propia personalidad. Ahora bien, es preciso determinar si el divorcio incausado merece dicha restricción.

\subsubsection{SObRE EL PERJUICIO SOCIAL}

Se suele afirmar que al ser el divorcio la ruptura de una institución tan significativa para la sociedad, es esta misma la que asume sus consecuencias. En otras palabras, que la sociedad en general es la que experimenta los perjuicios ocasionados por el divorcio.

La situación pudo haber sido tal hace muchos años. La Iglesia Católica monopolizaba la regulación y el entendimiento sobre las relaciones familiares en la sociedad. Tal era el valor moral y religioso del matrimonio, que Juan Larrea Holguín enfatizó, bajo el subtítulo "Carácter sacramental del matrimonio", el carácter metafísico del matrimonio:

Pero hay algo que eleva al matrimonio a un plano incomparablemente superior. Se trata de una elevación que exigió una intervención directa de Dios: la elevación a la dignidad de sacramento. Eso es como una nueva creación: no de la nada, sino de algo preexistente: pero una creación, porque aparece un nuevo ser: el sacramento; el medio específico de santificación; el símbolo real e intrínseco de otra realidad; la seńal sensible de la gracia que se da a los hombres: participación de la vida divina. ${ }^{41}$

Si esto se entiende por matrimonio, entonces el perjuicio social no era más que una consecuencia directa y natural del divorcio. Si para la sociedad y para el Estado el matrimonio es lo mismo que para Larrea Holguín, entonces el divorcio es la mayor aberración moral que el hombre puede realizar.

Pero mucho ha cambiado. Esta institución ya descendió de los cielos y ahora es gobernada por preceptos terrenales, mundanos y civiles. El matrimonio ya dejó de ser la manifestación sagrada más pura de la existencia. Se convirtió en una institución jurídica creada por el hombre, una ficción útil al igual que todo el derecho, que busca formalizar y registrar una relación sentimental, además de regular las consecuencias patrimoniales que de esta surgen. Ya no es más que eso.

41 Juan Larrea Holguín, Manual Elemental de Derecho Civil en Ecuador, Tomo III (Quito: Corporación de Estudios y Publicaciones, 1998), 158. 
Consecuentemente, el matrimonio incide únicamente dentro de la vida privada de los cónyuges. Entendiendo al divorcio como lo que es, no puede generar un perjuicio social en sentido abstracto. Al respecto, la Corte Constitucional ha manifestado que "la decisión de ejercer el derecho a contraer matrimonio se trata de un asunto de la esfera privada", y que "el Estado solo puede proscribir acciones que inciden objetivamente en el bienestar de terceros". ${ }^{42} \mathrm{Si}$ el matrimonio pertenece a la esfera íntima de las personas, no hay razones para sostener algo distinto sobre su disolución.

Ya que el divorcio no genera perjuicio social alguno, es preciso reconocer la posibilidad de que vulnere derechos de las personas íntimamente vinculadas a él. El análisis demanda primero dilucidar si los derechos del cónyuge se ven violentados. Después, es preciso proceder al punto medular, sobre los derechos de los hijos en común de esa relación.

\subsubsection{DERECHOS DEL OTRO CÓNYUGE}

El matrimonio es disoluble. Tanto lo es, que existe una figura civil destinada particularmente para ese fin: el divorcio. Es una posibilidad real que tiene sus propias consecuencias jurídicas. Todo matrimonio, jurídicamente, es susceptible de disolución. No hay sorpresa ni imprevisibilidad alguna en esto.

Cuando se entendía al divorcio como una sanción, era más sencillo argumentar que los derechos del cónyuge inocente (víctima) fueron vulnerados. Esta distribución de roles — culpable e inocente- artificialmente creada por el sistema de divorcio por causales, narraba la historia por sí sola: el cónyuge culpable vulneró los derechos del cónyuge inocente y, por lo tanto, es merecedor de una sanción. A pesar de que no tenía sustento considerable, en un sistema como tal no era posible explicarlo de otra manera.

Pero el divorcio ahora es un remedio y así lo ha entendido la jurisprudencia ecuatoriana. Ya no es el resultado de una vulneración de derechos. Si algún derecho fue vulnerado, esa conducta tendrá su consecuencia jurídica respectiva. Pero esos efectos jurídicos no tendrán relevancia alguna para decidir sobre la procedencia o improcedencia del divorcio. Por consiguiente, en un sistema que entiende al divorcio como un remedio ya no es necesario distribuir jurídicamente los roles de culpable e inocente. La vulneración de derechos ya no debe ser el pretexto jurídico que un sistema por causales necesita para aprobar el divorcio.

Dentro de este contexto, se ha empezado a entender al divorcio como un derecho. El derecho que tiene el cónyuge de, si lo considera conveniente,

42 Sentencia No. 11-18-CN/19, pág. 37. 
disolver el vínculo jurídico para evitar la prolongación de sus desavenencias. Es, en otras palabras, el derecho para remediar una situación desfavorable. El derecho español ya lo ha reconocido como tal y en cierto modo también lo ha hecho el derecho francés:

El legislador reconoce un auténtico derecho al divorcio que viene a incrementar la larga lista de derechos subjetivos recientes y la consagración del derecho al divorcio confiere un nuevo impulso a la voluntad de descasar. Ya sea recíproca o aislada, la voluntad adquiere un papel mayor dentro de los supuestos de divorcio. ${ }^{43}$

Entenderlo como un derecho subjetivo es absolutamente compatible con la nueva noción de divorcio remedio. Al ser una solución, no es más que el derecho a poder tomar una decisión que resuelva una situación problemática. Por lo tanto, cabe cuestionarse si el derecho al divorcio - ejercido paralelamente con el derecho al libre desarrollo de la personalidad - vulnera el derecho del cónyuge que no se quiere divorciar. ¿Merece una limitación?

A este respecto, la Corte Constitucional se ha manifestado sobre la limitación a los derechos. En particular, lo hizo para argumentar que el matrimonio igualitario no vulnera derechos de las parejas heterosexuales. "Los límites a los derechos tienen sentido cuando afectan el ejercicio de derecho de otros" ${ }^{44}$ Los derechos que son capaces de hacer tal cosa son conocidos como "derechos-poderes". Son aquellos cuyos titulares los ostentan "de forma excluyente y acumulativa". Por ejemplo, los derechos patrimoniales, por su naturaleza, pueden fácilmente degenerar en un abusivo poder de mercado o en un monopolio. Es decir, son derechos que pueden progresivamente expandirse, cual bola de nieve, hasta el punto en el que no permiten que un competidor ingrese en el mercado. El legislador, para limitar su poder, exige de ellos considerables sumas en concepto de tributos y mantiene una entidad dedicada únicamente a controlar los posibles abusos. Otro claro ejemplo es el de los derechos políticos. La Constitución consagra el derecho de participación ${ }^{45}$, pero no limitarlo sería abrir las puertas a un autoritarismo puro y duro. Para evitarlo, la Constitución limita el período de mandato presidencial, faculta a la Corte Constitucional y a la Asamblea Nacional para revocar un estado de excepción, contempla la figura del juicio político, etc. ${ }^{46}$ Estos derechos deben ser limitados para que sus titulares no abusen de ellos restringiendo derechos de terceros.

43 Nathalie Peterka, "El divorcio francés tras la ley de 26 de mayo de 2004. Un divorcio bajo la influencia de la voluntad", en Familia, matrimonio y divorcio en los albores del siglo XXI. Jornadas Internacionales sobre las Reformas de Derecho de Familia. Potencias y Comunicaciones, dir. Carlos Lasarte Álvarez (Madrid, Idadfe, UNED y El Derecho, 2006), 19. Citado en Nelly Minyersky, El impacto del proyecto del Código Civil y Comercial de la Nación en instituciones del derecho de familia, Pensar en Derecho, http://www.derecho.uba.ar/publicaciones/pensar-en-derecho/revistas/0/el-impacto-del-proyecto-del-codigo-civil-y-comercial-de-la-nacion-en-instituciones-del-derecho-de-familia.pdf.

44 Sentencia No. 11-18-CN/19, pág. 35

45 Artículo 61, Constitución de la República del Ecuador.

46 Sentencia No. 11-18-CN/19, pág. 35. 
El derecho a solicitar unilateral e injustificadamente el divorcio no es un derecho-poder. En primer lugar, no lo es porque no es un derecho excluyente. El cónyuge titular de aquel derecho no priva al otro cónyuge de la misma facultad. Ambos, en cualquier momento, podrían decidirlo por sí mismos y el derecho del uno no restringe el del otro. En segundo lugar, no es un derecho-poder porque tampoco es un derecho acumulativo. Es claro ver cómo un derecho patrimonial o político puede ampliarse progresivamente. Estos impiden a terceros ejercer algún tipo de competencia, ya sea en el ámbito político o en un mercado determinado. No sucede lo mismo con el derecho a solicitar el divorcio. Por su naturaleza, este no puede ampliarse gradualmente, y por lo tanto no es un derecho susceptible de acumulación. Al no ser un derecho-poder, la limitación al derecho de solicitar unilateralmente el divorcio no se encuentra justificada.

Por esa razón, con el divorcio incausado no se vulneran derechos del cónyuge que no se quiere divorciar. La titularidad del derecho que ostenta su cónyuge no restringe su titularidad del mismo derecho.

Se dirá que un divorcio unilateral por afecto no correspondido destruye emocionalmente al otro cónyuge. Es un perjuicio real, sin duda. Es muy probable que sus sentimientos hacia esa persona hayan sido muy fuertes. Pero no todo perjuicio encuentra un respaldo en el derecho. De ser el caso, toda relación de noviazgo fallida terminaría en los tribunales. Sus consecuencias serán morales, si se quiere, pero en nada importan, en general, al derecho.

\subsubsection{DERECHOS DE LOS HIJOS EN COMÚN}

El divorcio incausado merece especial cuidado particularmente por los efectos que podría producir en los descendientes menores de edad de la relación. Es menester examinar si los derechos de los hijos o hijas se ven vulnerados por un divorcio incausado.

La importancia del bienestar del niño no está en discusión. A pesar de que la procreación ya dejó de ser uno de los fines del matrimonio, ${ }^{47}$ en el caso de que existan descendientes estos revisten de la mayor relevancia para la relación y constituyen el pilar fundamental de la institución matrimonial. Por lo tanto, todo lo que sobre esta institución se regule debe siempre tener en cuenta el interés superior del niño. ${ }^{48}$

Para empezar, es preciso acotar que el divorcio incausado no es una figura

47 Sentencia No. 10-18/CN, Corte Constitucional del Ecuador, 12 de junio de 2019.

48 A pesar de ser un concepto jurídico indeterminado cuyos alcances no siempre son claros, su extrema importancia no se cuestiona. Ver, Farith Simon Campańa, Interés superior del niño: técnicas de reducción de la discrecionalidad abusiva (Quito: Ediciones Iuris Dictio, 2014), 1. 
distinta al divorcio por causales. Los efectos del divorcio son los mismos: se disuelve la sociedad conyugal (de haberla) y desaparecen los derechos, restricciones y obligaciones que surgen del estatus jurídico de cónyuge. ${ }^{49}$ Lo nuevo es el camino jurídico que se debe recorrer para su consecución. Por eso, si se considera que el divorcio incausado vulnera derechos de los niños, no hay razón para sostener lo contrario sobre el divorcio por causales. No hay un criterio justificado de diferenciación, pues no son dos tipos de divorcio distintos; son solo dos vías alternas para obtenerlo: la pacífica y la contenciosa.

Y las personas se divorcian de todas maneras. Si se ha roto el vínculo afectivo dentro del hogar y uno de los cónyuges quiere divorciarse, el sistema causalista no lo impedirá. Su abogado creará artificialmente una de las causales. Una artimaña común consiste en solicitarle al cónyuge que abandone el hogar para que se configure la causal de abandono dentro de seis meses. Aunque lo pretenden, las causales no impiden el divorcio. Pero sí lo hacen más largo, conflictivo y doloroso.

Un divorcio incausado no difiere, en cuanto a los hijos se refiere, con el divorcio por causales. Ambos divorcios —en realidad es solo un mismo tipo de divorcio- generan los mismos efectos jurídicos con relación a los hijos. Además, el cónyuge que se quiere divorciar lo hará de todas maneras. El sistema causalista no es verdaderamente un impedimento. Por lo mismo, afirmar que el divorcio incausado es atentatorio contra los derechos de los niños no se sostiene si no se dice lo mismo sobre la institución del divorcio en general (ya sea causado o incausado). Para solucionar el problema que esta postura identifica, sería necesario retrotraerse hasta el año 1903 cuando entró en vigor la Ley de Matrimonio Civil, pero no es un problema que se originaría con el divorcio incausado.

En segundo lugar, lo que sí hace el divorcio por causales es prolongar un conflicto innecesariamente. Los cónyuges se disputan el divorcio ante los estrados, exponiendo sus intimidades ante un juez mientras que su rencor va expandiéndose conforme pasan las etapas procesales.

La Corte Nacional de Justicia conoció un caso en el que el cónyuge demandó el divorcio por adulterio cuando se enteró de que la hija a la que su cónyuge dio a luz no era de él (a pesar de que así lo creía). Para efectos de la sentencia, la Corte transcribió en mayúsculas, mencionando los nombres y apellidos de todos los miembros de la familia, su declaración:

Sin embargo, desde hace mucho tiempo atrás y particularmente hace unos seis meses atrás [...] por versiones de mi propia cónyuge [nombres y apellidos], así como de vecinos, parientes y amigos, se ha venido manifestando que yo no soy

49 Una pequeńa diferencia es que en el divorcio por causales existen ciertas sanciones civiles para el cónyuge "infractor". Sin embargo, estas sanciones civiles en nada afectan al nińo. 
el padre de la menor, lo que me ha llevado a venir dudando de la paternidad de la niña porque tengo las razones fundadas para ello. (minúsculas son propias). ${ }^{50}$

Es difícil creer que la exhibición de estas confidencialidades tiene como exclusivo fin declarar el divorcio. Es penoso que la menor esté en la mitad de este proceso judicial y se sienta como un artefacto cuya propiedad se disputa. Si lo que prima es el interés superior del niño, sería prudente que el Estado evite con un divorcio incausado - un proceso judicial de naturaleza tan conflictiva.

Pese al daño que genera un largo proceso judicial combativo, es más perjudicial para un niño "crecer y desarrollarse en un ambiente hostil [...] que afecta sensiblemente su proceso de desarrollo y formación". ${ }^{51}$ En tal sentido, la Corte Constitucional colombiana ha expresado que "para los niños y cónyuges puede resultar más benéfico la separación de sus padres y no crecer en un ambiente hostil". ${ }^{2}$

El divorcio incausado no vulnera los derechos de los hijos de la relación. Lo que hace es evitar que sufran innecesariamente involucrándolos en el transcurso de un proceso judicial duelista, además de librarlos de la posibilidad de que crezcan en un entorno doméstico indeseable que atente contra su sano desarrollo.

\subsection{SOBRE EL DERECHO A LA INTIMIDAD FAMILIAR}

Un sistema de divorcio por causales obliga a los cónyuges a exhibir su vida privada. Partiendo de la premisa de que los procesos son públicos en el Ecuador, los cónyuges no exponen sus intimidades solo ante un juez, sino ante toda la sociedad. Además, toda causal que invoquen para divorciarse debe ser probada. Se deberá probar el adulterio, la falta de armonía en el hogar, los tratos crueles, etc. ¿Cómo probar estos hechos tan íntimos de las personas? La dificultad probatoria es evidente. Probar el adulterio, por ejemplo, reviste de una dificultad inexplicable. En la práctica los jueces se han resignado y están dispuestos a contentarse con prueba indiciaria. Sin embargo, el problema es más profundo que la complejidad probatoria. No solo que es difícil probar, sino que también son hechos que no deben requerir prueba alguna.

Esto no significa que todo lo que ocurra dentro del hogar deba ser ajeno al Estado. Hay asuntos domésticos que el Estado debe conocer. Si hay violencia intrafamiliar, por ejemplo, es necesario que el Estado no deje impunes a los agresores y active sus respectivos medios penales de coacción. Es apenas

\footnotetext{
50 Resolución No. 231-2014, Corte Nacional de Justicia, Sala de la Familia, Nińez, Adolescencia y Adolescentes Infractores, 17 de octubre de 2014.

51 Movilla, Divorcio incausado, 53.

52 Sentencia No. C-985/10, Expediente D-8134, Corte Constitucional de Colombia, 2 de diciembre de 2010.
} 
lógico también que, si existen amenazas graves contra la vida del cónyuge, el Estado debe intervenir en protección de las víctimas. La misma lógica aplica para todo el resto de las causales que contengan violencia, tentativa de delitos, tratos crueles, o, en general, todo tipo de conductas punibles. Estos comportamientos no deben quedar en la impunidad.

No obstante, existe una gran diferencia entre hacer averiguaciones domésticas para castigar actos antijurídicos y, por el otro lado, inmiscuirse dentro del hogar para decidir autoritariamente sobre la procedencia del divorcio. Lo primero se justifica porque la impunidad del agresor es indeseada. Lo segundo, en cambio, excede las atribuciones del Estado al pretender enrumbar moralmente a las personas decidiendo por ellas sobre la admisibilidad de su divorcio y sobre el destino de su estado civil. Es invasivo y arbitrario.

La Constitución consagra "el derecho a la intimidad personal y familiar". ${ }^{53}$ A su vez, la Convención Americana sobre Derechos Humanos (en adelante $\mathrm{CADH}$ ) prescribe que "nadie puede ser objeto de injerencias arbitrarias o abusivas en su vida privada [o] en la de su familia". ${ }^{54}$ El Comité de Derechos Humanos desarrolla este derecho y afirma que cuando el artículo 11 numeral 2 de la CADH se refiere a "injerencias arbitrarias", incluye también a las posibles injerencias que comete la ley. ${ }^{55}$ No se limita a aquellas injerencias que únicamente tienen sustento de hecho y no de derecho.

La interconexión entre el derecho a la vida privada e intimidad familiar con el derecho al libre desarrollo de la personalidad, es evidente. En tal sentido, la Corte Constitucional cita a la Corte Interamericana de Derechos Humanos (en adelante Corte IDH) para explicar su estrecha relación:

La protección del derecho a la vida privada no se limita al derecho a la privacidad, pues abarca una serie de factores relacionados con la dignidad de la persona, incluyendo, por ejemplo, la capacidad para desarrollar su propia personalidad, aspiraciones, determinar su identidad y definir sus relaciones personales. El concepto de vida privada engloba aspectos de la identidad física y social, incluyendo el derecho a la autonomía personal, desarrollo personal y el derecho a establecer y desarrollar relaciones con otros seres humanos y con el mundo exterior. ${ }^{56}$

$\mathrm{Al}$ respetar el derecho a la intimidad familiar de las personas, se está también permitiendo un adecuado desarrollo de sus personalidades. Es armónico con

53 Artículo 66.20, Constitución de la República del Ecuador.

54 Art. 11.2, Convención Americana sobre Derechos Humanos, San José, 22 de noviembre de 1969.

55 Observación general No. 16 del Comité de Derechos Humanos sobre su $32^{\circ}$ período de sesiones, Comité de Derechos Humanos, 1988, párr. 4

56 Caso I.V. vs. Bolivia, Corte Interamericana de Derechos Humanos [Corte IDH], Excepciones Preliminares, Fondo, Reparaciones y Costas, Sentencia de 30 de noviembre de 2016, párr. 152; Caso Fernández Ortega y otros vs. México, Corte IDH, Excepción Preliminar, Fondo, Reparaciones y Costas, Sentencia de 30 de agosto de 2010; Caso Artavia Murillo y otros ("Fecundación in vitro") vs. Costa Rica, Corte IDH, Excepciones Preliminares, Fondo, Reparaciones y Costas, Sentencia de 28 de noviembre de 2012. Serie C No. 215, párr. 129, párr. 143. Citado en Sentencia No. 11-18-CN/19, Corte Constitucional del Ecuador, párr. 178. 
la dignidad de los cónyuges y con el respeto que merecen sus intimidades domésticas.

Así, el divorcio por causales vulnera vehementemente el derecho a la privacidad familiar. La intromisión estatal dentro de la vida íntima de las personas solo es justificada en cuanto tenga como fin castigar delitos o conductas antijurídicas. Pero realizar estas averiguaciones solo para decidir sobre la procedencia del divorcio es autoritario e intrusivo.

Para entender el alcance de estas injerencias, es menester tener presente qué tipo de información es la que los jueces, en un sistema de divorcio por causales, están obligados a conocer. La Corte Suprema de Justicia, por ejemplo, tuvo que utilizar como prueba para un divorcio - cuya causal invocada era la de actitud hostil — que la cónyuge de un chofer se había apoderado del radio de la cooperativa para proferir "expresiones soeces" en contra de su pareja, las cuales lo humillaron gravemente porque tanto los pasajeros como sus colegas conductores las escucharon. ${ }^{57}$ ¿En realidad son hechos que el Estado debe conocer?

\subsubsection{Pequeña nota sobre el adulterio}

El adulterio dejó de ser un delito en el Ecuador en el año $1983 .{ }^{58}$ A pesar de esto, todavía tiene efectos jurídicos al ser una de las causales de divorcio. En el año 2015, en Argentina entró en vigor el Código Civil y Comercial de la Nación (en adelante CCyC). ${ }^{59}$ Fue revolucionario, pues instauró en dicho país un sistema incausado de divorcio. En Argentina, el adulterio ya no tiene consecuencia jurídica alguna.

Es evidente que la fidelidad conyugal es de gran relevancia para una convivencia armoniosa y pacífica. Sin duda, la fidelidad es absolutamente significativa para la sociedad y es un deber moral de la más alta valía. No obstante, autores como Susan Turner Saelzer sostienen que, a pesar de su extrema importancia social, es inadecuado concederle al adulterio consecuencias jurídicas, pues no son más que enunciados netamente morales. ${ }^{60}$ Afirma que, con la entrada en vigor del CCyC, el adulterio "subsiste como valor ético o moral en la vida matrimonial, sin perjuicio de que desaparece de la órbita jurídica" ${ }^{61}$ Es acertado, pues la simple enunciación de deberes morales excede del objetivo de la ley. La

57 Resolución de recurso de casación, Corte Suprema de Justicia, Tercera Sala de lo Civil y Mercantil, 21 de marzo de 2006. Gaceta Judicial. Ańo CVII. Serie XVIII, No. 2. Página 500.

$58 \mathrm{El}$ adulterio como delito fue suprimido por el artículo final del Código de Procedimiento Penal, Ley No. 143, Registro Oficial 511 de 10 de junio de 1983.

59 Código Civil y Comercial de la Nación (Argentina), Ley 26.994 de 1 de agosto de 2015.

60 Susan Turner Saelzer, "Infidelidad, culpa, divorcio e indemnización de perjuicios en el derecho matrimonial argentino y chileno", Revista de Derecho Privado 35 (Julio 2018): 105-128, https://doi.org/10.18601/01234366.n35.05.

61 Ibíd, 115. 
ley no debe normar la moralidad. El adulterio tiene formidables implicaciones ético-morales, pero en nada debe interesar al derecho.

\subsection{SOBRE EL DERECHO DE LOS INDIVIDUOS A LA PROTECCIÓN FAMILIAR}

El artículo 67 de la Constitución manifiesta que no se reconocerá un solo tipo de familia y que el "Estado la protegerá como núcleo fundamental de la sociedad y garantizará condiciones que favorezcan integralmente la consecución de sus fines”. ${ }^{62}$ ¿Esto significa que el Estado tiene el deber de prolongar el matrimonio a toda costa?

La Corte Nacional de Justicia expresó con claridad que el deber de protección no siempre incluye al deber de prolongación:

La protección que el Estado debe a la familia [...] debe ser entendida como la defensa de un núcleo social que asegure la convivencia en armonía, el bienestar y el desarrollo integral de sus miembros, y aquello implica que el matrimonio no debe perdurar, cuando no cumple con estos fines y resulta atentatorio a la dignidad humana. ${ }^{63}$

La familia, como piedra angular de la sociedad, merece protección estatal. La Constitución en el artículo 67 les reconoce tal derecho a sus integrantes. Pero es preciso cuestionarse cuál es la naturaleza de ese verbo. Por un lado, se puede interpretar forzosamente al artículo como que lo que se debe hacer es mantener el vínculo matrimonial a como diere lugar. Pero por el otro lado, una interpretación sistemática de dicho artículo exige que la protección de la familia sea más que su artificial prolongación. El Estado debe proteger el vínculo matrimonial — como cualquier otra constitución familiar- pero tampoco debe perennizar su degeneración.

Además, la Corte Constitucional colombiana ha sido bastante clara al mencionar que cuando las circunstancias fundacionales del matrimonio han desaparecido, el Estado debe establecer mecanismos eficientes para su terminación:

El imperativo constitucional en lo que refiere a la protección y promoción de la institución familiar no es la duración del matrimonio - como una de sus formas de constitución- . Es lograr la estabilidad y armonía del grupo familiar, no solo como presupuesto social, sino como condición sine qua non para permitir la realización humana y el desarrollo integral de cada uno de sus miembros en un clima de respeto, óptima convivencia y libre expresión de sus sentimientos y emociones.

62 Artículo 67, Constitución de la República del Ecuador.

63 Resolución No. 018-2015, Corte Nacional de Justicia, Sala de la Familia, Niñez, Adolescencia y Adolescentes Infractores, 5 de febrero de 2015. 
Dichos objetivos no se garantizan ni se logran manteniendo vigente el contrato matrimonial, en aquellos casos en los que surgen diferencias, desavenencias o conflictos entre los cónyuges que hacen imposible [...] la convivencia y que perturban la estabilidad familiar. ${ }^{64}$

Como bien han expuesto ambas cortes, el deber de protección a la familia incluye garantizar también su sana y expedita disolución. Prolongar forzosamente una relación malherida es un remedio más dañino que la propia enfermedad.

\section{LEgiSLACIONES COMPARADAS}

El divorcio incausado ya ha sido adoptado por varios países en el mundo. Cada vez, naturalmente, gana terreno en normativas contemporáneas.

\subsection{Argentina}

El CCyC argentino entró en vigencia en el año 2015. Este cuerpo normativo cambió el paradigma en el divorcio conyugal. Ahora, el CCyC regula un solo tipo de divorcio: el incausado. ${ }^{65}$ El capítulo primero del Libro II, que trata sobre las relaciones de familia, se titula "Principios de libertad e igualdad". ${ }^{66}$ Desde un inicio, el CCyC proclama a la libertad como uno de los principios rectores en materia familiar.

Para la transformación, varios puntos y argumentos fueron recurrentes. Primero, se cuestionó con alta rigurosidad el rol de cuidado que el Estado debe asumir dentro de la relación familiar. Además, se enfatizó en la vulneración del derecho al libre desarrollo de la personalidad que un sistema causalista generaba. Asimismo, se hizo hincapié en todos los conflictos que son producto del proceso de este divorcio contencioso. ${ }^{67}$

En ese sentido, los fundamentos del anteproyecto del CCyC argentino mencionaron que "la experiencia judicial ha demostrado el alto nivel de destrucción y desgaste emocional al que se someten los cónyuges y sus familias cuando se opta por el divorcio contencioso" ${ }^{68}$ Por lo tanto, el divorcio incausado también es un intento de apaciguar los problemáticos procesos judiciales de

64 Sentencia C-985/10, párr. 3.

65 Florencia P. Galeazzo. "El nuevo paradigma del divorcio express vs. el divorcio sanción". Sistema Argentino de Información Jurídica (Agosto 2016). http://www.saij.gob.ar/florencia-galeazzo-goffredo-nuevo-paradigma-divorcio-express-vs-divorcio-sancion-dacf160393-2016-08-10/123456789-0abc-defg3930-61 fcanirtcod?\&o=4\&f=Total\%7CFecha/2016/08\%7CEstado\%20de\%20Vigencia\%5B5\%2C1\%5D\%7CTema/Derecho\%20civil\%5B3\%.

66 Artículos 402 y ss., Código Civil y Comercial de la Nación (Argentina). Ley 26.994 de 1 de agosto de 2015.

67 Galeazzo, El nuevo paradigma del divorcio, 16.

68 Comisión Para La Elaboración Del Proyecto De Ley De Reforma, Actualización y Unificación de los Códigos Civil Y Comercial De La Nación, Fundamentos del Anteproyecto del Código Civil y Comercial General de la Nación, 2012, 63. 
divorcio. Pretende "colaborar a superar la ruptura matrimonial de la manera menos dolorosa posible". ${ }^{69}$

\subsection{ESPAÑA}

En España también rige un sistema de divorcio incausado. Desde el año 2005 se modificó el Código Civil y la Ley de Enjuiciamiento Civil en materia de separación y divorcio. La exposición de motivos anota que adoptar un divorcio incausado protege y promueve la dignidad de los cónyuges. Además, que eso supone "favorecer al libre desarrollo de la personalidad"..$^{70}$

La exposición de motivos ha ilustrado otros puntos dignos de consideración. Afirma que perpetuar el conflicto entre los cónyuges con un divorcio contencioso es inconveniente. No solo para los cónyuges, sino también para sus familias que se ven indirectamente incluidas en la disputa. También expone que este sistema causalista, al condicionar el divorcio a la prueba de una causal particular, sacrifica la voluntad de los cónyuges "por razones inaprensibles" a los mismos. La única "causal”, en este sistema, es el ejercicio del derecho al libre desarrollo de la personalidad. Finalmente, esta exposición de motivos hace hincapié en la libertad como valor fundamental del ordenamiento jurídico español. Así pues, el ordenamiento español encontró urgente una reforma que permita reflejar a la libertad en su institución matrimonial. ${ }^{71}$

\subsection{MÉXICO}

A partir del 2008, México consagra la figura de divorcio incausado o exprés. No es el único tipo de divorcio en este país, pues también existe el divorcio necesario o el divorcio por mutuo consentimiento. México tiene un particular requisito, y es que el divorcio incausado solo puede ser accionado después de un año de celebrado el contrato matrimonial. El fin de esta disposición es brindar a los cónyuges un período de reflexión para que no tomen la decisión de una manera apresurada. ${ }^{72}$

Dentro de la exposición de motivos y las consideraciones oficiales a esta reforma, se expresa una argumentación concordante con la del resto de ordenamientos. Así, manifiesta que la familia surge por razones naturales, en la que dos personas se unen para emprender un proyecto de vida común. Es por eso, expresan los considerandos, que se trata a estas disposiciones como de orden

69 Ibíd.

70 Exposición de motivos, Ley 15/2005 de 2005 de Espańa [Por la cual se modifican el Código Civil y la Ley de Enjuiciamiento Civil en materia de separación y divorcio]. Referencia BOE-A-2005-11864 de 8 de julio de 2005.

71 Id.

72 Exposición de motivos, Decreto No. 443 [El cual modifica el Código Civil del Estado de México y del Código de Procedimientos Civiles del Estado de México]. Gaceta Oficial de Gobierno de 3 de mayo de 2012. 
público y de interés social. Sin embargo, afirma que no hay razón para ignorar una realidad social en la que el índice de divorcios por falta de armonía doméstica, por situaciones irremediables, es muy elevado. ${ }^{73}$ Por lo mismo, consideran que el divorcio es un remedio o una solución para diferencias irreconciliables.

Sostiene también que es la obligación del Estado proteger a la familia. No obstante, que también es la obligación del Estado "velar por el derecho de toda persona a un ambiente adecuado para su desarrollo y bienestar sustentado en la libertad e igualdad". ${ }^{74}$

\subsection{SUECIA}

En Suecia solo existe un tipo de divorcio: el incausado. Si ambos cónyuges están de acuerdo, o solo uno lo está, es indiferente. Es particular porque, en ciertos casos, tiene una limitación temporal: no se puede solicitar el divorcio dentro de los próximos seis meses desde que se verifica alguna de las siguientes condiciones:

a. ambos cónyuges solicitan este período para reflexionar y reconsiderar la decisión;

b. uno de los dos cónyuges vive permanentemente con un hijo propio que es menor de 16 y está bajo su custodia; y

c. solo uno de los cónyuges desea terminar la relación matrimonial. ${ }^{75}$

Lo que queda claro, sin embargo, es que el divorcio no requiere de justificación ni causal alguna. A pesar de exigir el período de reflexión de seis meses, el Estado sueco no interfiere con la vida privada de los cónyuges ni se inmiscuye en situaciones domésticas privadas. Si uno de los cónyuges quiere divorciarse, lo hará.

\section{Conclusiones}

El divorcio incausado es la mejor respuesta que el Estado ecuatoriano puede adoptar para compatibilizar su régimen familiar con la primacía de la libertad. Varios ordenamientos jurídicos ya han tomado este camino. Un sistema por causales pretende no solo perennizar situaciones irremediables, sino también

75 Jeremy D. "Sweden Divorce Requirements". Suiza: The Law Office of Jeremy D. Morley International Family Law. https://bit.ly/33wk7No.
} 
impartir paternalistamente lecciones morales a los cónyuges. Esto excede del papel que al Estado compete protagonizar. Las personas deben poder decidir sobre sus propios asuntos y con mucha mayor razón si son de tal trascendencia como su matrimonio o su respectiva disolución. La felicidad de las personas no debe quedar en manos del Estado.

Es imperativo, por lo tanto, que el ordenamiento jurídico ecuatoriano respete los derechos fundamentales de los individuos en un ambiente en el que prime la voluntad y la autonomía individual. Las personas, incluso en contra de la voluntad de su cónyuge, deben poder escoger el camino que mejor les parezca para sus propias vidas. Deben poder, ante todo, autodeterminarse y escoger el rumbo de las dimensiones más personales e íntimas de su condición humana. De esta manera, el régimen civil matrimonial ecuatoriano será regulado en un entorno de tolerancia, respeto, autonomía individual y libertad. Nada puede ser más urgente que esto.

A pesar de que mucho queda por hacer, este trabajo pretende dar un pequeño paso hacia la modernización del derecho de familia. Es necesario, y es un deber de las personas de hoy, descongelar aquello que ha quedado inmóvil e inerte. Aquello que se volvió insensible a los temporales, al pasar de los años, al sentir de la gente. La sociedad ecuatoriana del siglo XXI dejará de aceptar pasivamente un sistema creado por y para personas que ya no existen, y empezará, cual arquitecta de su porvenir, a adaptar el derecho con base en sus necesidades más urgentes. Es una responsabilidad que debe ser asumida. 
